\title{
Utilization of Waste Glass Micro-particles in Producing Self-Consolidating Concrete Mixtures
}

\author{
Yasser Sharifi*, Iman Afshoon, Zeinab Firoozjaei, and Amin Momeni
}

(Received September 19, 2015, Accepted April 3, 2016, Published online May 25, 2016)

\begin{abstract}
The successful completion of the present research would be achieved using ground waste glass (GWG) microparticles in self-consolidating concrete (SCC). Here, the influences of GWG microparticles as cementing material on mechanical and durability response properties of SCC are investigated. The aim of this study is to investigate the hardened mechanical properties, percentage of water absorption, free drying shrinkage, unit weight and Alkali Silica Reaction (ASR) of binary blended concrete with partial replacement of cement by 5, 10, 15, 20, 25 and $30 \mathrm{wt} \%$ of GWG microparticles. Besides, slump flow, V-funnel, L-box, J-ring, GTM screen stability, visual stability index (VSI), setting time and air content tests were also performed as workability of fresh concrete indicators. The results show that the workability of fresh concrete was increased by increasing the content of GWG microparticles. The results showed that using GWG microparticles up to maximum replacement of $15 \%$ produces concrete with improved hardened strengths. From the results, when the amount of GWG increased there was a gradual decrease in ASR expansion. Results showed that it is possible to successfully produce SCC with GWG as cementing material in terms of workability, durability and hardened properties.
\end{abstract}

Keywords: self-consolidating concrete (SCC), ground waste glass (GWG), hardened properties, binary blended concrete, cementing material.

\section{Introduction}

Use of recycled materials in construction is among the most attractive options because of the large quantity consumptions of the materials, relatively low quality requirements and widespread construction sites. The main applications include a partial replacement for aggregate in asphalt concrete, as fine aggregate in unbond base course, pipe bedding, landfill gas venting systems and gravel backfill for drains (Afshoon and Sharifi 2014; Sharifi et al. 2015; Shi et al. 2005). Due to the ever strict environmental regulations, waste treatment costs and limited availability of disposal sites, the development of new and cost-effective waste management practices has become increasingly significant in recent years (Alp et al. 2008). Waste reuse and recycling are among modern society's environmental priorities, and considerable effort is being devoted to achieve these objectives. Green construction materials play an important role in the sustainable development of the construction industry. Concrete, the most widely used construction material, absorbs natural mineral resources and

Department of Civil Engineering, Vali-e-Asr University of Rafsanjan, Rafsanjan, Iran.

*Corresponding Author; E-mail:

yasser_sharifi@yahoo.com; y.sharifi@vru.ac.ir

Copyright (c) The Author(s) 2016 This article is published

with open access at Springerlink.com should be considered to reduce energy consumption during construction. A sustainable concrete design includes minimizing both the quantity of global carbon dioxide $\left(\mathrm{CO}_{2}\right)$ released and the energy consumed to produce concrete and the various components required (Zong et al. 2014). This huge size of production consumes large amounts of energy and is one of the largest contributors to $\mathrm{CO}_{2}$ release. Accordingly, there is a pressing demand to minimize the quantity of cement used in the concrete industry (Alya et al. 2012).

The Self-consolidating concrete (SCC) was first developed in Japan in the late 1980s (Okamura and Ouchi 2003). Over the last decades, SCC as a new generation of high-performance concrete, has been known as a significant progress in concrete industry and consequently considered as the subject of extensive research studies (Nikbin et al. 2014). SCC's unique property gives it significant constructability, economic and engineering advantages (Uysal 2012; Mahmoud et al. 2013; Lotfy et al. 2015). Moreover, SCC can be pumped to a great distance and increases the speed of construction. Changes to mix design or placing of the material can lead to the modifications of the porous structure and consequently permeability of the material. The fines content of SCC is higher than in normally-vibrated concrete (NVC) and the absence of compacting lowers the risks inherent in the process, either from excessive vibration or from insufficient vibration (Valcuendea et al. 2012). In order to avoid separation of large particles in SCC, viscosity increasing additives or fillers are utilized. An additive to increase the 
viscosity is often used when concrete is cast under water and for SCC in tunnels. Mineral admixtures like fly ash, glass filler, limestone powder, silica fume or quartzite fillers may be used in the mixture to increase the viscosity of SCC (Bingol and Tohumcu 2013). The use of mineral additives in concrete or cement is one of the main trends in the development of concrete technology; at the same time it is an important element of a sustainable development strategy. It enables the properties of the concrete to be improved, especially in the aspect of resistance to the aggressive influence of the environment, as well as to obtain significant economic benefits (Ponikiewski and Golaszewski 2014). Apart from the significant effect on hardened concrete properties, the incorporation of mineral additives in concrete is also known to have a considerable effect on its fresh properties. The use of such powders provides greater cohesiveness by improving the grain-size distribution and particle packing. Moreover, their high pozzolanic activity leads to a further particle packing enhancement that is achieved by the pozzolanic products and acts complementary to the physical action (Sfikas et al. 2014).

Glass in general is a highly transparent material formed by melting a mixture of materials such as silica, soda ash, and $\mathrm{CaCO}_{3}$ at high temperatures followed by cooling during which solidification occurs without crystallization. Glass is widely used in our lives through manufactured products such as sheet glass, bottles, glassware, and vacuum tubing (Park et al. 2004). The concept of using waste glass in concrete is not new; early efforts were conducted in the 1960s to use crushed waste glass as a replacement for aggregate. However, these attempts were not satisfactory due to the strong reaction between the alkali in cement and the reactive silica in glass, namely ASR (Alya et al. 2012). In this phenomenon the amorphous silica in glass is susceptible to attack by the alkaline environment and would depolymerize to form a monomer $\mathrm{Si}(\mathrm{OH})_{4}$, which could further react with alkalis such as $\mathrm{Na}^{+}, \mathrm{K}^{+}$and $\mathrm{Ca}^{2+}$ to form the ASR gel. This ASR gel can absorb water and swell inside the microstructure of concrete, resulting in internal stress. Once the internal stress exceeds the strength of concrete, severe cracking and damage may occur (Du and Tan 2013). When waste glass is collected, different color glass is often intermixed. Mixed color glass cannot be recycled, however, because a mixing of coloring agents results in an unpredictable and uncontrollable color in the new glass. Machines are capable of using optical sensors to efficiently sort large glass pieces by color; however, sorting small glass pieces is not economical and much of this unrecyclable glass cullet is then landfilled. As the economic and environmental consequences of landfilling rise, the incentive to reuse glass cullet has grown. The concrete industry is one of the potential ways of reusing millions tons of glass cullet per year either as aggregate or supplementary cementitious material (SCM) (Mirzahosseini and Riding 2014). Although work on the use of finely ground glass as a pozzolanic material also started as early as 1960 s, most of the work in this area is relatively recent, and has been encouraged as a result of continual accumulation of waste glass and its consequent environmental issues (Shayan and $\mathrm{Xu}$ 2006). On the other hand, limited work (one study by this time) has been carried out on the application of ground glass as SCM in SCC (Liu 2011).

A study on the properties of fresh self-consolidating glass concrete (SCGC) investigated by Wang and Huang (2010). They reported that, the slump flow of self-compacting glass concrete (SCGC) increased with higher glass sand replacement. V-funnel and U-test indicated that, when the glass sand replacement increases, the time required to flow and pass through the space between the steel bars increases, mainly because the unit weight is reduced. The air content and unit weight would be raised with glass sand contents decreasing. Recycled glass replacement as fine aggregate in SCC also investigated by Sharifi et al. (2013). Fresh results indicate that the flow-ability characteristics have been increased as the waste glass incorporated to paste volume. Nevertheless, compressive, flexural and splitting tensile strengths of concrete containing waste glass have been shown to decrease when the content of waste glass is increased.

Shayan and $\mathrm{Xu}$ (2006) investigated the performance of glass powder (GLP) as a pozzolanic material in concrete. They reported that mixtures containing GLP also performed satisfactorily with respect to drying shrinkage and alkali reactivity, and there were indications that GLP reduces the chloride ion penetrability of the concrete, thereby reducing the risk of chloride induced corrosion of the steel reinforcement in concrete. The results demonstrated that GLP can be incorporated into $40 \mathrm{MPa}$ concrete at dosage rates of $20-30 \%$ to replace cement without harmful effects. The use of GLP provides for considerable value-added utilization of waste glass in concrete and significant reductions in the production of greenhouse gases by the cement industry.

Jain and Neithalath (2010) studied the chloride transport in fly ash and glass powder modified concretes. Rapid chloride permeability (RCP), non-steady-state migration (NSSM) and steady state conduction (SSC) tests are performed on plain and modified concretes. Results shown the glass powder modified concretes demonstrate similar or lower RCP values as compared to the fly ash modified concretes of the same cement replacement level whereas the steady state conductivities are lower for the fly ash modified mixtures. They reported that the NSSM coefficients are lower for the fly ash modified concretes even when the initial conductivities are similar to those of plain or glass powder modified concretes.

Liu (2011) studied incorporating ground glass in SCC. They conclude that, to keep the filling ability constant, the inclusion of ground glass would require an increase in water/ powder ratio and a reduction in superplasticizer dosage. These did not change the passing ability, but degraded the consistence retention and hardened properties such as strength but not to a prohibitive extent.

Carpenter and Cramer (1668) also reported that powdered glass was effective in reducing ASR expansion in accelerated mortar bar tests, similar to the effects of fly ash, silica fume and slag.

Waste glass as a supplementary cementitious material in concrete was investigated by Federico and Chidiac (2009). 
They reported that the similarity between the ASR and pozzolanic reactions observed for waste glass in concrete suggests that they are closely related and may be simply various stages of one another subject to several controlling factors, including particle size, pore solution, and chemical composition. So far, just the research which has been conducted by Liu (2011) investigated the behavior of SCC containing GWG microparticle substitute as cementing material, and the lack of a comprehensive study on the engineering response of SCC incorporating GWG which partially replaced with cement was evident.

\section{Materials}

\subsection{Cement}

Ordinary Portland Cement (OPC) meeting the requirements of ASTM C150 (2009) was used in preparation of concrete mixtures. The chemical and physical properties of cement are given in Table 1. The micro-particle size distribution pattern of the used OPC is also illustrated in Fig. 1.

\subsection{Waste Glass}

Waste glass (Fig. 2) provided from Rafsanjan-Iran, then in the laboratory is ground by using an electric mill (Fig. 3), for $10 \mathrm{~min}$ to a maximum particle size of 100 micron meters $(\mu \mathrm{m})$ before it was used as a cement replacement material. It was added to the concrete mixtures as a secondary binder replacing up to $30 \%$ by weight of cement. Incorporation of high-volume mineral admixtures reduces heat of hydration as cement content in concrete was reduced and thus rate of hydration reduced. The total heat of hydration produced by the pozzolanic reactions with mineral admixtures is considered as half of the average heat of hydration produced by Portland cement. Due to the reduced heat of hydration, it leads to improvement of rheology properties and reduces

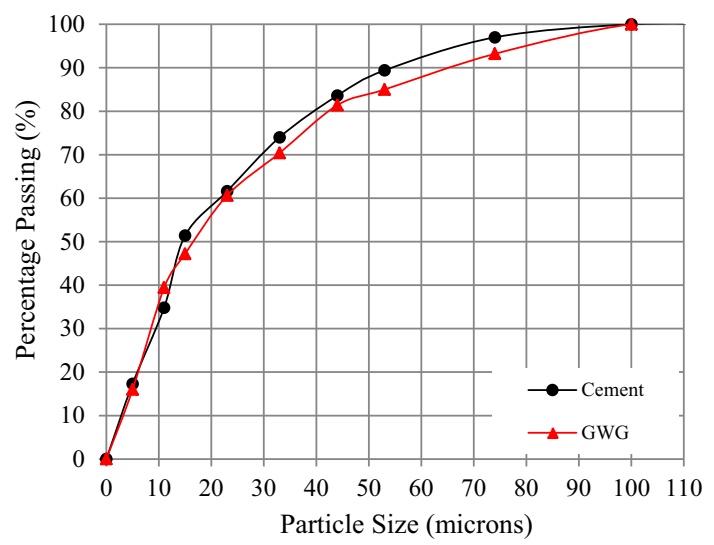

Fig. 1 Particle size distribution for binders.
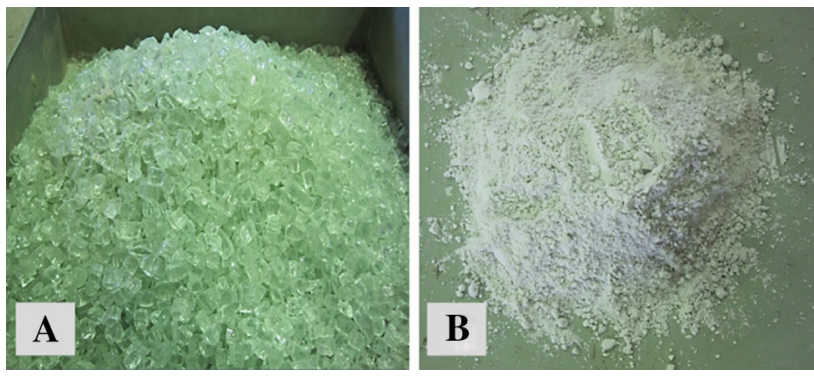

Fig. 2 Waste glass used in this study: before grounding (a), after grounding (b).

thermally-induced cracking of concrete as well as long term properties of concrete (Nuruddin et al. 2014). The chemical and physical properties of the waste glass is given also in Table 1.

\subsection{Aggregates}

Locally available sand from natural sources was used in the present experimental investigation. The aggregates used in this experiment are both angular and circler angle together

Table 1 Chemical analysis and physical properties of cement and GWG_compressive strength of cement.

\begin{tabular}{|c|c|c|c|c|c|c|}
\hline \multicolumn{3}{|c|}{ Chemical analysis } & \multicolumn{4}{|c|}{ Physical properties } \\
\hline Compound (\%) & Cement & Glass & & \multicolumn{2}{|c|}{ Cement } & Glass \\
\hline $\mathrm{SiO}_{2}$ & 21.74 & 70.5 & $\begin{array}{c}\text { Water absorption } \\
(\%)\end{array}$ & \multicolumn{2}{|c|}{-} & 0.17 \\
\hline $\mathrm{Al}_{2} \mathrm{O}_{3}$ & 5 & 2.6 & Specific density & \multicolumn{2}{|c|}{3.15} & 2.50 \\
\hline $\mathrm{Fe}_{2} \mathrm{O}_{3}$ & 4 & - & $\begin{array}{l}\text { Specific surface } \\
\text { area }\left(\mathrm{cm}^{2} / \mathrm{g}\right)\end{array}$ & \multicolumn{2}{|c|}{2900} & 2480 \\
\hline $\mathrm{CaO}$ & 63.04 & 5.7 & $\begin{array}{c}\text { Setting time (final) } \\
\text { (min) }\end{array}$ & \multicolumn{2}{|c|}{170} & - \\
\hline $\mathrm{MgO}$ & 2 & 2.9 & $\begin{array}{c}\text { Setting time (initial) } \\
(\min )\end{array}$ & \multicolumn{2}{|c|}{120} & - \\
\hline $\mathrm{Na}_{2} \mathrm{O}$ & 2.3 & 16.3 & $\begin{array}{c}\text { Autoclave } \\
\text { expansion (\%) }\end{array}$ & \multicolumn{2}{|c|}{0.1} & - \\
\hline $\mathrm{K}_{2} \mathrm{O}$ & 1 & 1.2 & \multirow{3}{*}{$\begin{array}{c}\text { Compressive } \\
\text { strength }\left(\mathrm{kg} / \mathrm{cm}^{2}\right)\end{array}$} & 220 & 3 days & - \\
\hline $\mathrm{SO}_{3}$ & 2.9 & 0.2 & & 275 & 7 days & - \\
\hline LOI & 1.3 & - & & 380 & 28 days & - \\
\hline
\end{tabular}



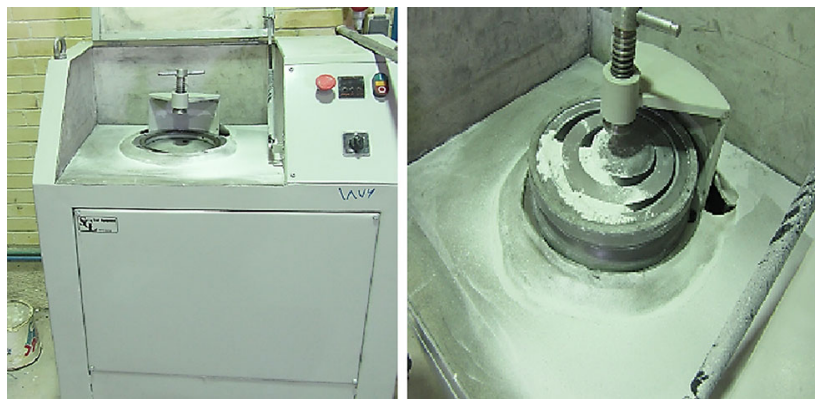

Fig. 3 Electric mill used in this study.

that are from river materials. The fine aggregate was the natural sand free from impurities with minimum and maximum size of 0.3 and $4.75 \mathrm{~mm} .19 .5 \mathrm{~mm}$ nominal maximum size dolomite is used as coarse aggregate and minimum size of coarse aggregate is $4.75 \mathrm{~mm}$. Dolomite powder was used replacing of sand that is smaller than 300x. Table 2 shows the physical properties of coarse and fine aggregates. The aggregate was kept in a condition greater than saturated surface dry (SSD) level. Aggregate particle size distribution was determined in accordance with ASTM C33 (2008) and is presented in Fig. 4. The particle size distribution indicated that it was continuously distributed with $35 \%$ over the size range of $9.5-19.5 \mathrm{~mm}$. The particle size distribution was well-graded with over $47 \%$ of the sand over the size range of $0.3-1.18 \mathrm{~mm}$.

\subsection{Water}

Regular tap water was used as mixing water, according to the ASTM C94 specifications (2009).

\subsection{Super-Plasticizer}

In order to improve the workability of high performance concrete, polycarboxylic ether based high range water reducer (HRWR) namely P10-3R was used. Table 3 shows the properties of HRWR according to the ASTM C494 (2010).

\section{Mix Proportions}

A total of seven SCC mixes were made and their detailed mix proportions are presented in Table 4 . These included one control mix (Mix-0) and six mixes (Mix-5 to Mix-30) made by replacing cement with $5,10,15,20,25$ and $30 \%$ of GWG microparticles partially. For all SCCs, the amount of the cementations used was generally maintained at

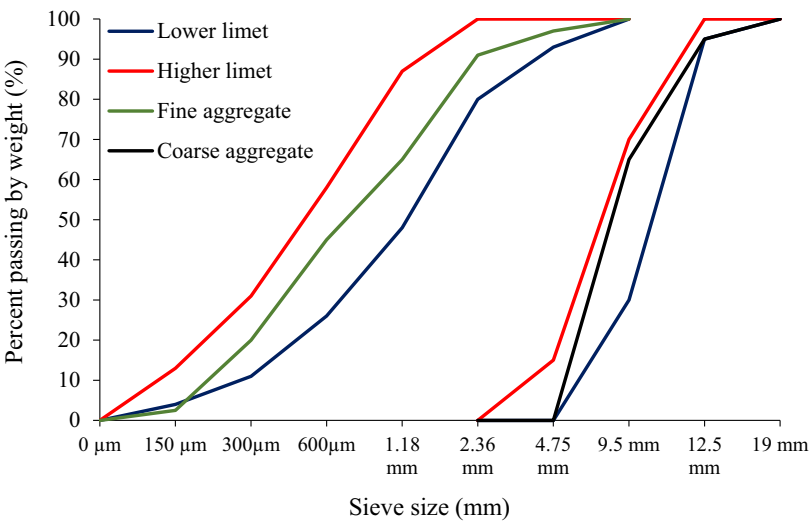

Fig. 4 Particle size distribution of fine and coarse aggregates.

$400 \mathrm{~kg} / \mathrm{m}^{3}$. Coarse and fine aggregates contents were maintained at 700 and $950 \mathrm{~kg} / \mathrm{m}^{3}$, respectively. The $W / B$ ratio was 0.51 for all mixes. Super-plasticizer was also used in the mixtures at the ratio of $1.4-1.1 \%$ of binder materials by weight for providing the desired fluidity of the SCC. In the production of SCCs, the mixing sequence and duration are very important. The batching sequence consisted of homogenizing the fine and coarse aggregates for $30 \mathrm{~s}$ in a rotary planetary mixer, then about half of the mixing water introduced. It continued for $1 \mathrm{~min}$. thereafter, cement were added and the mixing was resumed for another minute. Finally, the super-plasticizer with remaining water was introduced, and the concrete was mixed for $3 \mathrm{~min}$ and then left for $2 \mathrm{~min}$ rest. Eventually, the concrete was mixed for additional 2 min to complete the mixing sequence. Concrete mixes were designed in a way to give a slump flow of $680 \pm 30 \mathrm{~mm}$ which was achieved by using the super-plasticizer at varying amounts. For this, trial batches were produced for each mixture till the desired slump flow was obtained.

\section{Casting, Curing and Testing}

\subsection{Fresh Concrete Tests}

According to European Federation of Producers and Contractors of Specialist Products for Structures (EFNARC) guide for making self-compacting concrete (2005), a concrete mixture can only be classified as SCC if the requirements for filling, passing, and segregation resistivity characteristics are fulfilled. Various tests have been used in present experimental study to investigate the properties of

Table 2 Physical properties of aggregates.

\begin{tabular}{c|c|c}
\hline Properties & Fine aggregate & Coarse aggregate \\
\hline \hline Specific gravity & 2.73 & 1565 \\
\hline Bulk density $\left(\mathrm{kg} / \mathrm{m}^{3}\right)$ & 1590 & 47.58 \\
\hline Void content $(\%)$ & 36.71 & 0.32 \\
\hline Water absorption (\%) & 1.09 & \\
\hline
\end{tabular}


Table 3 Properties of the super-plasticizer.

\begin{tabular}{c|c|c|c}
\hline Items & Standards quality & Testing results & Regulatory \\
\hline \hline Density $\left(20^{\circ} \mathrm{C}\right)\left(\mathrm{g} / \mathrm{cm}^{3}\right)$ & $0.938-1.146$ & $1.1 \pm 0.02$ & ASTM-C494 \\
\hline $\mathrm{PH}\left(20{ }^{\circ} \mathrm{C}\right)$ & $5.4-7.4$ & 7 & - \\
\hline Chlorine $(\mathrm{ppm})$ & $\leq 2400$ & 500 & ASTM-C494 \\
\hline Color & - & Dark green & - \\
\hline
\end{tabular}

Table 4 Concrete design mix proportions.

\begin{tabular}{|c|c|c|c|c|c|c|c|}
\hline \multirow[t]{2}{*}{ Detail mix } & \multirow[t]{2}{*}{ Mix } & \multicolumn{2}{|c|}{ Aggregates $\left(\mathrm{kg} / \mathrm{m}^{3}\right)$} & \multicolumn{2}{|c|}{$\begin{array}{c}\text { Cementitious material } \\
(B)\left(\mathrm{kg} / \mathrm{m}^{3}\right)\end{array}$} & \multirow[t]{2}{*}{$W / B$} & \multirow[t]{2}{*}{$\mathrm{SP}^{\mathrm{a}}(\%)$} \\
\hline & & Coarse & Fine & GWG & Cement & & \\
\hline $\begin{array}{c}\% \text { GWG }+ \\
100 \% \mathrm{C}\end{array}$ & Mix-0 & 768 & 1060 & 0 & 400 & 0.51 & 1.4 \\
\hline $\begin{array}{l}5 \% \text { GWG } \\
+95 \% \mathrm{C}\end{array}$ & Mix-5 & 766 & 1058 & 20 & 380 & 0.51 & 1.4 \\
\hline $\begin{array}{r}10 \% \mathrm{GWG} \\
+90 \% \mathrm{C}\end{array}$ & Mix-10 & 763 & 1055 & 40 & 360 & 0.51 & 1.4 \\
\hline $\begin{array}{r}15 \% \mathrm{GWG} \\
+85 \% \mathrm{C}\end{array}$ & Mix-15 & 762 & 1054 & 60 & 340 & 0.51 & 1.4 \\
\hline $\begin{array}{r}20 \% \mathrm{GWG} \\
+80 \% \mathrm{C}\end{array}$ & Mix-20 & 760 & 1050 & 80 & 320 & 0.51 & 1.4 \\
\hline $\begin{array}{r}25 \% \mathrm{GWG} \\
+75 \% \mathrm{C}\end{array}$ & Mix-25 & 758 & 1047 & 100 & 300 & 0.51 & 1.2 \\
\hline $\begin{array}{r}30 \% \mathrm{GWG} \\
+70 \% \mathrm{C}\end{array}$ & Mix-30 & 756 & 1046 & 120 & 280 & 0.51 & 1.1 \\
\hline
\end{tabular}

${ }^{a}$ Percent by mass of binder $(B)$.

fresh concrete mixes compositions. So far no single method or combination of methods has achieved universal approval and most of them have their adherents. Hence, each mix design should be tested by more than one test method for different workability parameters. Fresh concrete properties of SCCs were determined by using the slump (Diameter, $\mathrm{T}_{500}$ and $\mathrm{T}_{\text {final }}$ ), V-funnel $\left(\mathrm{T}_{0}\right)$, J-ring (step height, diameter, $\mathrm{T}_{500}$ and $\left.\mathrm{T}_{\text {final }}\right)$, GTM screen stability and L-box $\left(h_{1} / h_{2}, \mathrm{~T}_{200}\right.$, $\mathrm{T}_{400}$ and $\mathrm{T}_{\text {final }}$ ) tests according to EFNARC (2005). Besides, the setting time and air content tests were measured for SCCs according to ASTM C403 (2008) and ASTM C231 (2009), respectively.

\subsection{Hardened Concrete Tests}

\subsubsection{Compressive Strength of Concretes}

Compressive strength test usually gives an overall picture of the quality of concrete, because strength is directly related to the structure of the hydrated cement paste. The compression test is an important test to determine the strength development of the concrete specimens (Hameed et al. 2012). It was defined as the maximum load sustained divided by the cross-sectional area of the sample. We used three $100 \mathrm{~mm}$ cube specimens for determined the compressive strength SCCs. This test were performed on 3, 7, 14, 28, 42, 56, 70 and 91 day old specimens.

\subsubsection{Tensile and Flexural Strength of Concretes}

For the evaluation of the tensile strength of concrete, there are three well-known methods: (i) the direct tensile strength, (ii) the splitting tensile strength and (iii) the flexural tensile strength (3- or 4-point loading). Due to the high degree of difficulty during execution, direct tensile strength test is rather scarce. It is possible to convert these test results from one to another. However, it is not quite clear whether these conversion factors can still be used for SCC (Craeye et al. 2014).

Splitting tensile strength was performed on three cylindrical molds $\varnothing 100 \mathrm{~mm} \times 200 \mathrm{~mm}$, at 3, 7, 14, 28, 42 and 56 day old specimens. After the specified curing period was over, the concrete cylinders were subjected to splitting tensile strength test by measured using a compressive machine with a loading capacity of 300 ton. The tests were carried out triplicately and average splitting tensile strength values were obtained.

The splitting tensile strength was determined using the following equation:

$$
F_{t}=2 P / \pi L d
$$

where $F_{t}$ is splitting tensile strength, $P$ is the maximum applied load indicated by testing machine, and $L$ and $d$ are the length and diameter of specimen, respectively. 
The flexural strength of concrete is conducted on prism of size $100 \times 100 \times 500 \mathrm{~mm}$. Six concrete prisms were casted for each concrete mix proportions for 28- and 56-days. Four point loading has been used to predict the flexural strength. The average modulus of rupture (flexural strength) was determined using the following expression:

$$
F_{c r}=P L / b d^{2}
$$

where $F_{c r}$ is the modulus of rupture; $P$ is the maximum applied load indicated by testing machine; and $L, b$ and $d$ are the average length, width and depth of specimen, respectively.

It is generally agreed that the splitting tensile strength test gives a better evaluation of the concrete's response to tensile stresses than that obtained from the modulus of rupture test (Druta et al. 2014).

\subsubsection{Unit Weight and Water Absorption of Concretes}

The unit weight (density) of hardened concrete was measured at the age of 28 days. This property predominately depends on aggregate density. Therefore, the replacement of cement may not change the density of the concrete remarkably (Beltran et al. 2014). Water absorption test is used to determine the amount of absorbed water under specified conditions which indicates the degree of porosity of a material (Siddique 2013). The water absorption test was conducted by completely immersing dried specimens (the mentioned specimens dried in the oven for $72 \pm 2 \mathrm{~h}$ ) in water and the amount of absorbed water percentage per mass after a specified time records. Here, it was conducted every day until the day of 10 after initial curing.

\subsubsection{Free Drying Shrinkage of Concretes}

Drying shrinkage can be defined as the volumetric change due to the drying of concrete. This change in volume of the concrete is not equal to volume of the water lost. The loss of free water occurs first; this causes little to no shrinkage. As the drying of the concrete continues, the adsorbed water held by hydrostatic tension in the small capillaries $(<50 \mathrm{~nm})$ is removed. The shrinkage due to this water loss is significantly larger than that associated with the loss of free water. The loss of water produces tensile stresses, which lead the concrete to shrink (Guneyisi et al. 2010). Free drying shrinkage of the SCCs specimens after drying was assessed at 1, 3, 7, 14, 28, 42, 56, 70 and 91 days. For this test, we used two beams of dimensions $(50 \mathrm{~mm} \times 50 \mathrm{~mm} \times 285 \mathrm{~mm})$. In this test, the specimens were removed from the molds at the age of $24 \mathrm{~h}$. At the end of the 28 day curing period, the specimens were stored in air until the time of testing. After then, the strain was measured at the special times.

\subsubsection{Alkali-Silica Reaction Test}

The expansion due to the ASR was determined on three prisms with dimensions of $25 \times 25 \times 285 \mathrm{~mm}$. A zero reading was taken after storing the prisms in distilled water at $80{ }^{\circ} \mathrm{C}$ for $24 \mathrm{~h}$. The mortar bars were then transferred and immersed in $1 \mathrm{~N} \mathrm{NaOH}$ solution at $80{ }^{\circ} \mathrm{C}$ until the testing time (Fig. 4). The expansion of the mortar bars was measured within $15 \pm 5 \mathrm{~s}$ after they were removed from the $80{ }^{\circ} \mathrm{C}$ water or alkali storage condition by using a length comparator. The measurements were conducted at the 1, 3, 7, 10, 14, 28 and 42 days. According to ASTM C 1260 the expansion of concrete 16 days after casting is classified as non-detrimental if it is below $0.10 \%$, as potentially detrimental if it is between $0.10 \%$ and $0.20 \%$ and as detrimental if it is over $0.20 \%$.

\section{Testing Procedure}

After curing, the following tests were carried out on the concrete specimens:

- Compressive strength test was conducted on concrete samples with BS 1881: Part 116 (1983), using a loading rate of $2.5 \mathrm{kN} / \mathrm{s}$;

- Cylinder tensile (splitting) strength test was done in accordance with ASTM C496 (2004), using a loading rate of $2.1 \mathrm{kN} / \mathrm{s}$;

- Flexural strength test was conducted in accordance with BS EN 1351:1997 (1997), using a simple beam with four point loading at a loading rate of $0.2 \mathrm{kN} / \mathrm{s}$;

- Unit weight test was conducted in accordance with BS EN-12390-7 (2009);

- The water absorption test was conducted in accordance with BS 1881: Part 122 (1983);

- ASTM C157 (2008) was used for free drying shrinkage;

- ASTM C1260 (2007) was used for the ASR test.

\section{Experimental Results and Discussion}

\subsection{Fresh Concrete Results}

The consistency and workability of SCC were evaluated using the slump flow, J-Ring, L-box, V-funnel, GTM screen stability, air content and setting time tests. The typical workability acceptance criteria for SCCs based on EFNARC (2005) are listed in Table 5. Properties of fresh SCCs are summarized in Table 6. As shown in Table 6, utilization of GWG increased workability of the fresh concrete. Similarly, slump flow time was always lower than $5 \mathrm{~s}$ for all of the concretes meeting the upper limit of EFNARC (2005). The results presented in Table 6 also indicated that, irrespective of $W / B$ ratio and $\mathrm{SP}$ dosage, the $\mathrm{V}$-funnel time shows a distinct tendency to decrease with increasing GWG content. For instance, Mix-0 had a V-funnel time of $8.15 \mathrm{~s}$ which decreased to $5.87 \mathrm{~s}$ as GWG introduced up to $30 \%$ by mass. From Table 6, the step height of the J-ring test, changed from $10 \mathrm{~mm}$ (Mix-0) to $12.5 \mathrm{~mm}$ (Mix-20) for SCC with $\mathrm{SP}=1.4 \%$, but this parameter for Mix-25 and Mix-30 mixes measured $14 \mathrm{~mm}$ and $16 \mathrm{~mm}$, respectively. It was observed that the $\mathrm{J}$ ring flow (slump flow with $\mathrm{J}$ ring) increased with increase in GWG content but this values were lower than the control mix (Mix-0). The J-Ring diameter was in the range of $645-664 \mathrm{~mm}$ and the difference in height 
Table 5 Acceptance criteria for SCC according to EFNARC.

\begin{tabular}{c|c|c|c|c|c}
\hline \multicolumn{2}{c|}{ Slump flow test } & \multicolumn{2}{c}{ V-funnel test } & \multicolumn{2}{c}{ L-box test } \\
\hline Slump flow classes & Slump flow (mm) & Viscosity classes & V-funnel times (s) & Passing ability classes & Blocking ratio \\
\hline \hline SF1 & $550-650$ & VF1 & $\leq 8$ & PA1 & $\geq 0.8$ with 2 bars \\
\hline SF2 & $660-750$ & VF2 & $9-25$ & PA2 & $\geq 0.8$ with 3 bars \\
\hline
\end{tabular}

Table 6 Properties of fresh SCC

\begin{tabular}{|c|c|c|c|c|c|c|c|}
\hline & Mix-0 & Mix-5 & Mix-10 & Mix-15 & Mix-20 & Mix-25 & Mix-30 \\
\hline \multicolumn{8}{|c|}{ Slump flow } \\
\hline Diameter $(\mathrm{mm})$ & 670 & 678 & 690 & 695 & 703 & 676 & 681 \\
\hline $\mathrm{T}_{500}(\mathrm{~s})$ & 4.96 & 4.12 & 3.64 & 2.79 & 1.68 & 2.49 & 2.02 \\
\hline T-Final (s) & 19.31 & 20.68 & 21.3 & 23.35 & 22.23 & 22.01 & 23.9 \\
\hline \multicolumn{8}{|c|}{ J-ring } \\
\hline $\begin{array}{l}\text { Step height } \\
(\mathrm{mm})\end{array}$ & 10 & 10.5 & 15 & 13.7 & 12.5 & 14 & 16 \\
\hline Diameter $(\mathrm{mm})$ & 655 & 657 & 650 & 660.5 & 664 & 655.5 & 645 \\
\hline $\mathrm{T}_{500}(\mathrm{~s})$ & 5.1 & 5.17 & 5.61 & 4.69 & 4.38 & 4.65 & 5.11 \\
\hline T-final (s) & 27.16 & 26.44 & 25.33 & 25.44 & 24.43 & 26.36 & 27.47 \\
\hline \multicolumn{8}{|c|}{ L-box } \\
\hline$h_{1 /} h_{2}$ & 0.84 & 0.93 & 0.92 & 0.96 & 0.99 & 0.95 & 0.97 \\
\hline $\mathrm{T}_{200}(\mathrm{~s})$ & 0.97 & 0.68 & 0.78 & 0.6 & 0.56 & 0.61 & 0.58 \\
\hline $\mathrm{T}_{400}(\mathrm{~s})$ & 1.73 & 1.42 & 1.51 & 1.11 & 0.94 & 1.06 & 0.96 \\
\hline T-final (s) & 13.67 & 12.45 & 13.55 & 12.24 & 10.36 & 11.54 & 10.67 \\
\hline \multicolumn{8}{|c|}{ V-funnel } \\
\hline $\mathrm{T}_{0}(\mathrm{~S})$ & 8.15 & 7.78 & 7.11 & 6.65 & 6.18 & 6.58 & 5.87 \\
\hline $\begin{array}{l}\text { GTM screen } \\
\text { stability }(\%)\end{array}$ & 8.7 & 8.2 & 6.9 & 7.6 & 8.1 & 7.1 & 5.6 \\
\hline Air content $(\%)$ & 3.8 & 3.7 & 3.1 & 2 & 1.2 & 2.5 & 3.3 \\
\hline \multicolumn{8}{|c|}{ Setting time } \\
\hline Initial set (min) & 416 & 430 & 450 & 457 & 480 & 410 & 395 \\
\hline Final set $(\mathrm{min})$ & 540 & 565 & 630 & 670 & 695 & 543 & 600 \\
\hline
\end{tabular}

was less than $20 \mathrm{~mm}$. The blocking ratio $\left(h_{2} / h_{1}\right)$ should be between 0.8 and 1.00. All mixtures of SCC are within this target range. The results presented in Table 6 also indicated that, in constant $W / B$ ratio, the blocking ratio $\left(h_{1} / h_{2}\right)$ shows a distinct tendency to increase with increasing GWG content. As presented in Table 6, with increase of GWG \% the segregation index (SI) increased up to $10 \%$. This reason may be due to increase in free water content and decrease in cohesion. The SI for the mixes was lower than $18 \%$ which is as per EFNARC (2005) standards and they were ranked to the SR2 class. In this study air content of all mixes between 1.2 and $3.8 \%$ (Table 6). Increasing GWG content caused air content decreased. This reason may be due to increase in free water content and filling ability of concrete mixes with
GWG. Table 6 shows that increasing the GWG content led to considerable increase of the initial and final sets. This can be attributed to increasing of free water in SCCs and smooth surface texture and low moisture absorption glass. But decrease in SP dosage could lead to the decrease of initial and final setting times of concrete for Mix-25 and Mix-30.

Figure 5's various tests have been used in present experimental study to investigate the fresh properties for mixes compositions.

\subsection{Hardened Concrete Results 6.2.1 Compressive Strength}

The compressive strength results of SCCs with GWG microparticles at curing periods up to 91 days are presented 

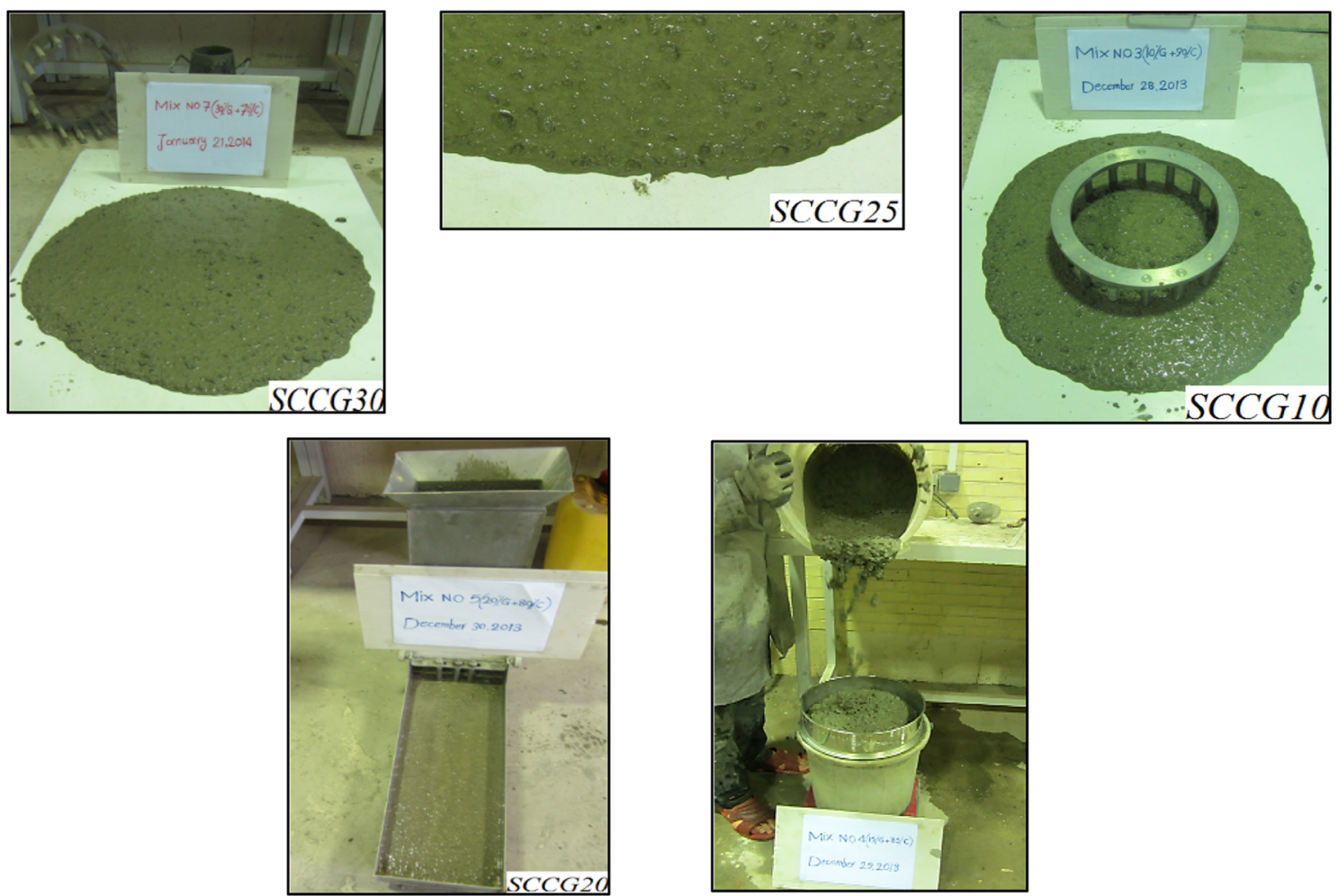

Fig. 5 Fresh properties tests (sump flow, J-ring, L-box, GTM and VSI test).

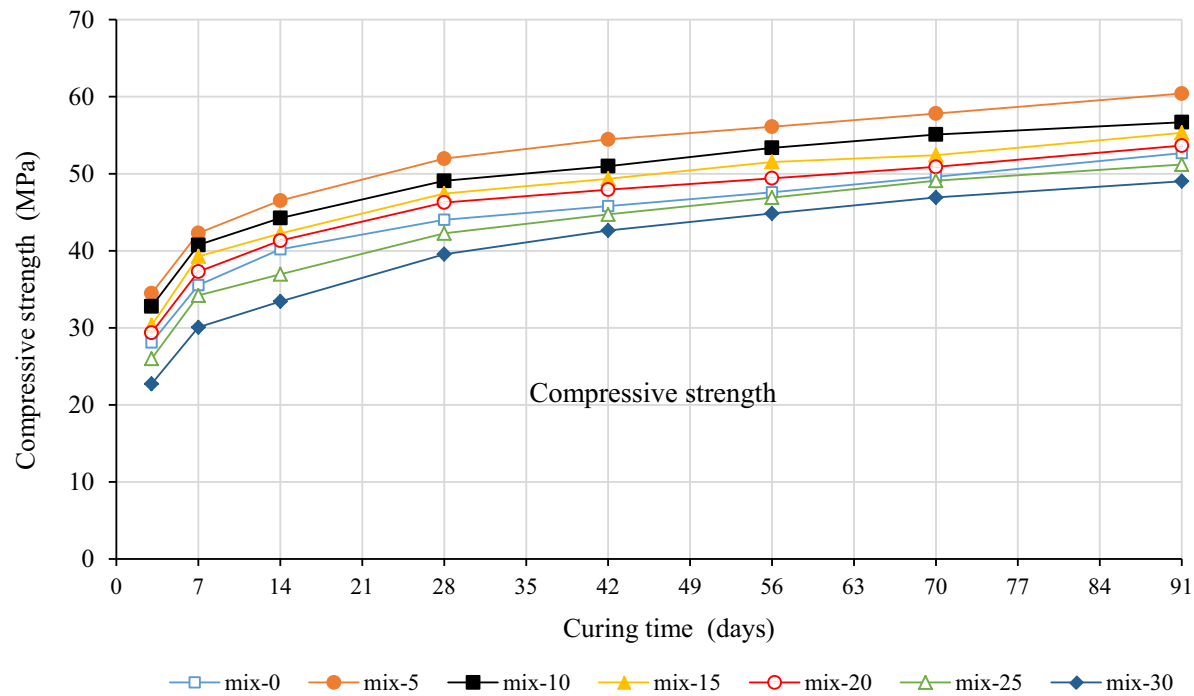

Fig. 6 Compressive strength of SCC with GWG microparticles as ages.

in Fig. 6. The rate of gain in compressive strength was rapid up to 14 days and then slowed down afterward. The 28-day compressive strength varied from 39.56 to $51.96 \mathrm{MPa}$ while the 91-day compressive strength differed from 49.03 to 60.41 MPa for different values of GWG microparticles. As can be seen from Fig. 7, GWG microparticles addition from 0 to $5 \%$ causes the compressive strength to increase 15.7 , 18 and $14.67 \%$, for 14,28 and 91 days, respectively. It is observed that the maximum compressive strength was achieved for specimen containing $5 \%$ GWG microparticles. Comparison of the results from the 3-, 7-, 14-, 28-, 42-, 56-, 70- and 91-day samples shows that the compressive strength increases with GWG up to $5 \%$ replacement and then it decreases, although the results of up to $20 \%$ replacement are still higher than those of the plain cementitious composite. This may be attributed to achievement of suitable workability of concrete which in turn causes more in compaction levels and improves compressive strength. This issue is highlighted in SCC mixtures when no compaction method is applied for molding and the compaction only performed by their own concrete weights. Second factor that may be caused an increase in compressive strength is the filler effect of GWG microparticles grains. It has been observed that Mix-25 and Mix-30 which containing 25 and $30 \%$ GWG achieved a slightly decrease in compressive strength about 2.8 and $6.9 \%$ compare to Mix- 0 , respectively. This may be due to 


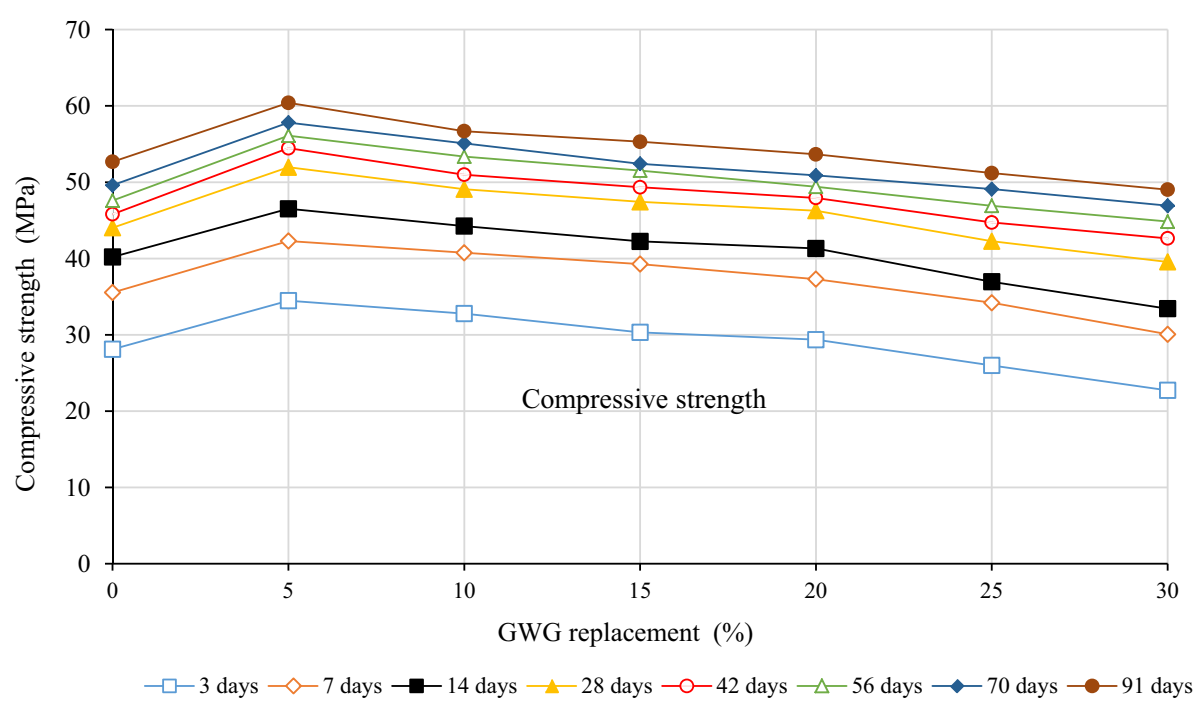

Fig. 7 Compressive strength versus GWG replacement as cementing material.

the fact that the quantity of GWG present in the mix is higher than the amount required to combine with the liberated lime during the process of hydration, thus leading to excess silica leaching out and causing a deficiency in strength as it replaces part of the cementitious material. Therefore, the optimum amount of GWG microparticle may be $20 \%$ as cement replacement, and the maximum strength achieved by $5 \%$ GWG replacement. Dyer and Dhir (2001) expressed that the maximum rate of hydration heat evolution drops as the Portland cement content is reduced and glass included. They noted this can be attributed to that any pozzolanic reaction the glass undergoes will occur at later stages and emits only minor quantities of heat. They also believed that the presence of green glass has little effect on the kinetics of Portland cement hydration. However, the production of portlandite is enhanced relative to the control, and $\mathrm{C}-\mathrm{S}-\mathrm{H}$ gel levels were found to be higher in the pastes containing glass.

Liu (2011) investigated the effect of waste glass inclusion as both cement and sand substitute in SCC. He found that inclusion of waste glass as cement and sand substitute in SCCs decreases the compressive strength. However he expressed that in terms of strength, glass could be a suitable candidate for addition in SCC. Federico and Chidiac (2009) considered the effect of waste glass as cement replacement in conventional concrete and reported that when cement replaced with waste glass between 10 and $20 \%$ the highest strength achieved. Our study corroborates their consequence in which, maximum strength happened in $5 \%$ GWG substitute as cementitious material, although inclusion of $20 \%$ of GWG gives similar compressive strength as the plain cementitious composite.

It should be noted that the particle sizes of GWG has a remarkable influence on the properties of mortar and concrete. Shao et al. (1999) investigated the response mortars containing glass which has been replace with cement partially. They found that the particle size has a clear influence on mortar behavior. Finer glass particles led to an increase in the reactivity of glass with lime, and hence improved compressive strength and decreased shrinkage. Chen et al. (2006) considered the performance of concretes with various waste E-glass particle amounts. The size distribution of glass particle was from 38 to $300 \mu$ and about $40 \%$ of E-glass particle was less than $150 \mu$. Based on the response of hardened concrete, optimum E-glass content was found to be $40-50 \%$ by mass. Oliveira et al. (2008) analyzed the effect of crushed glass of various sizes on mortars. The mixtures were prepared with replacing from 0 to $40 \%$ of the cement by glass. They concluded that mortars prepared with $45-75 \mu$ glass particles improve in terms of compressive strength, have a denser cementitious matrix and are less liable to expansive reactions such as ASR. As it was mentioned previously, in the present study the particle distribution of GWG is similar the cement particle distribution (Fig. 1), and the obtained results clarified the real behavior exactly.

\subsubsection{Splitting Tensile Strength}

Figure 8 shows the splitting tensile strength results which were also found to depend on the GWG microparticles contents. The 28-day splitting tensile strengths of Mix-5, Mix-10 and Mix-15 specimens showed an increase of 4.16, 6.62 and $1.57 \%$ more than 28 -day splitting tensile strength of Mix- 0 , respectively. Generally, the splitting tensile strengths of the concretes containing GWG microparticles increased with an increase in GWG content up to $15 \%$. As stated previously, this may be attributed to the chemical reaction between glass and calcium hydroxide that was up to the amount of products of hydration, basically calcium silicate hydrate. As expected, the tensile strength trend performance is similar the compressive strength approximately. When GWG content increased more, splitting tensile strengths decreased lower than those of the plain cement concrete (Mix-0). Similarly, this can be attributed to the fact that the quantity of GWG microparticles (pozzolan) exist in the mixture is higher than the required content to combine with the liberated lime during the process of hydration. Therefore, this leading to a deficiency in strength as it replaces part of the cementitious material but does not contribute to strength (Fig. 9). 


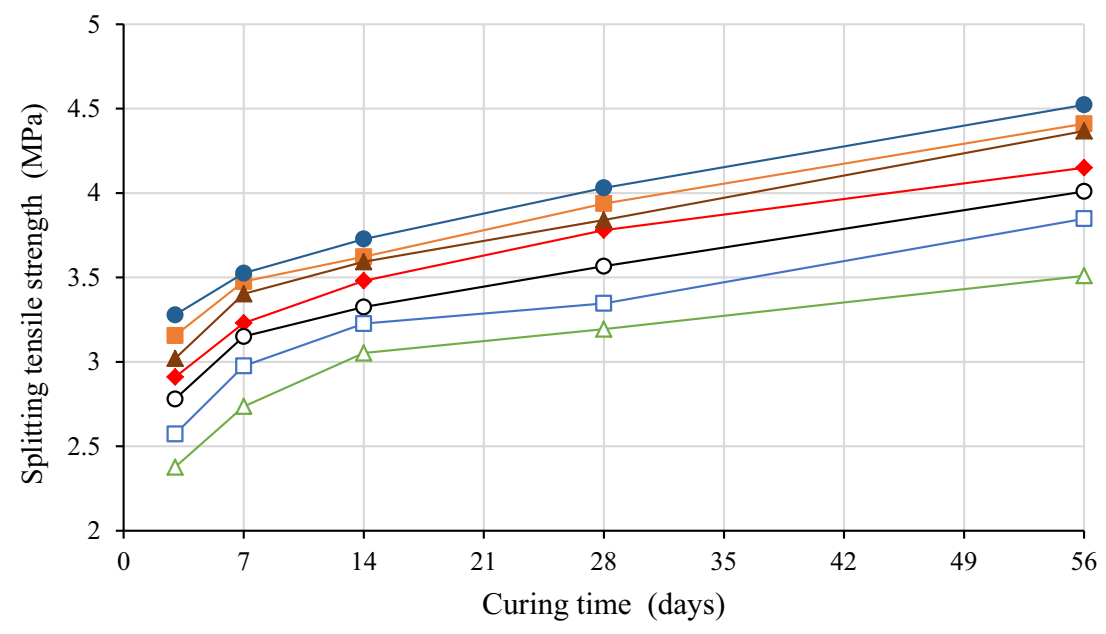

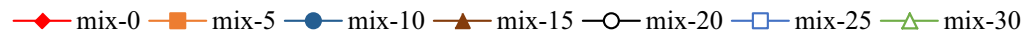

Fig. 8 Split tensile strength of SCC with GWG microparticles as ages.

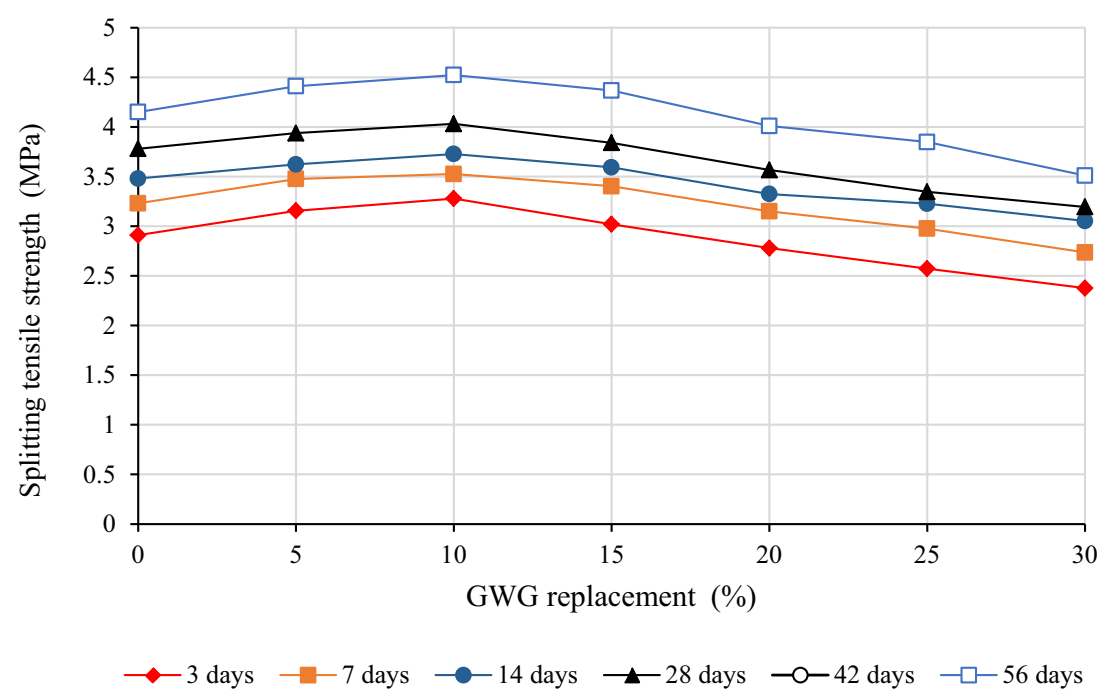

Fig. 9 Split tensile strength versus GWG replacement as cementing material.

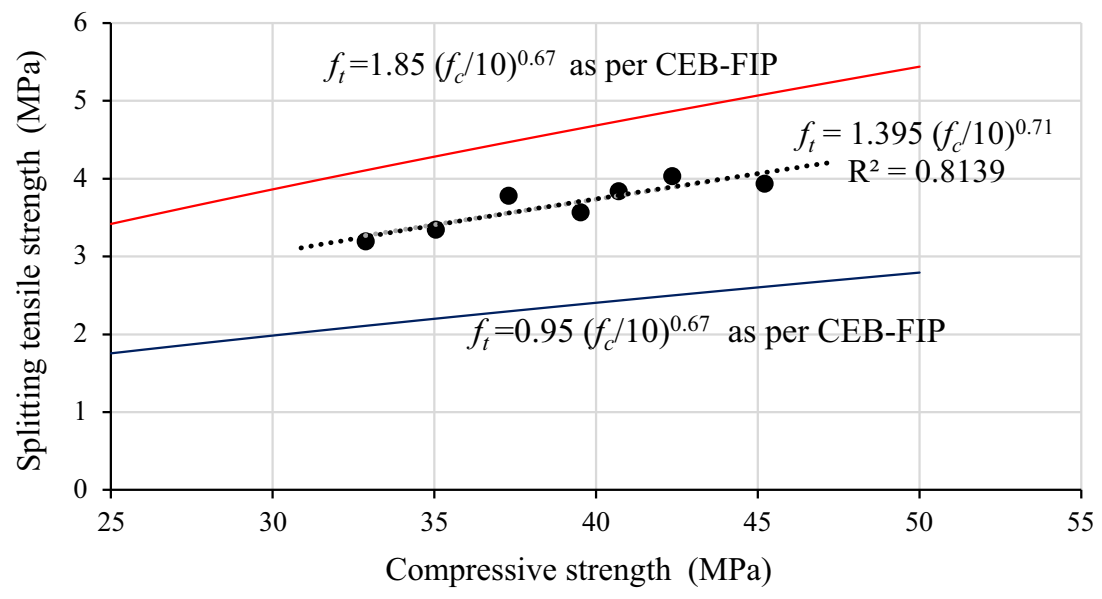

- Proposed equation - Lower bound Upper bound

Fig. 10 Variation of split tensile strength versus compressive strength. 
The average tensile strength was within the permissible values in accordance with the design specifications based CEB-FIP (1990) code provisions for conventional concrete. For design purposes, the tensile strength can be empirically taken as $0.45 \sqrt{F_{c u}}$, where $F_{c u}$ is the compressive strength (Jackson and Dhir 1996). The splitting tensile strength of the SCC mixtures versus corresponding 28-day cylindrical compressive strength was presented in Fig. 10. It should be noted that the $100-\mathrm{mm}$ cube compressive strength was converted to cylindrical strength by applying suitable conversation factor (Domone 1997). Accordingly, it can be seen that splitting tensile strength values of SCC with GWG lies in the range of bound value suggested by CEB-FIP code for normal concrete (1990). However, the mean relationship proposed by CEB-FIP model generally provided higher tensile strength value. This finding may be confirmed by the results of Parra et al. (2011), reported that at more advanced ages (28 and 90 days), there is a clearly higher tensile strength in normal vibration concrete than in SCC for the same compressive strength.

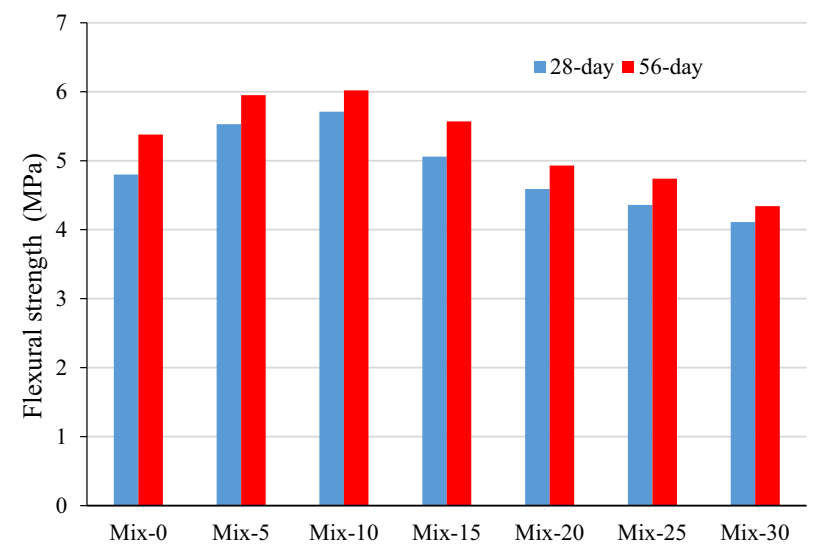

Fig. 11 Flexural strength of SCC with GWG microparticles in different ages.

\subsubsection{Flexural Strength}

The flexural strengths determined at 28 and 56 days as function of time in day are shown in Fig. 11. From Fig. 11 it can be seen that flexural strength increases by less than 20 for $10 \%$ GWG replacement, but at $30 \%$ the reduction was as much as $14 \%$ in the case of GWG replacement (at 28 days). When compared to that of the control mixture increasing amounts of GWG (5-15\%), generally increase the flexural strength. This implies that the material skeleton influences the flexural strength. Higher replacements of GWG also have resulted in decrease in strength. The decrease in the flexural strength of SCCs was about 8.36, 11.9 and 19.33\%, respectively, at 20, 25 and $30 \%$, GWG replacement in comparison with the control mixture (56 days) (Fig. 12). The experimental modulus of rupture compare with the empirical expression suggested in the design specifications that is $F_{c r}=0.75 \sqrt{F_{c u}}$ where $F_{c u}$ is the cube compressive strength (Jackson and Dhir 1996). Wang (2011) stated that the compressive strength, flexural strength and the tensile strength of the cement mortar with waste LCD glass powder decrease with increasing substitution amounts, while the property of the waste LCD glass powder with $10 \%$ substitution amount was similar to that of the control group, with respect to compressive strength and flexural strength. But here the $20 \%$ substitution amount gives similar strength as the control mix in term of hardened strength approximately (Mix-0).

\subsubsection{Unit weight}

The unit weight for different mixes with GWG percentages varying from 0 to $30 \%$ is shown in Fig. 13. Unit weight for the hardened specimens ranged between 2359 and $2395 \mathrm{~kg} /$ $\mathrm{m}^{3}$. Mix-15 with $2395 \mathrm{~kg} / \mathrm{m}^{3}$ showed the highest unit weight value among the mixtures. As GWG amount increased up to $10 \%$, unit weight of concrete increased accordingly. Mix-20, Mix-25 and Mix 30 were 0.37, 0.62 and $1.14 \%$ lower than that of the control concrete (mix-0), respectively. Utilizing pozzolanic materials (fly ash, slag, glass and etc.) in suitable quantities improved the workability of concrete and lead

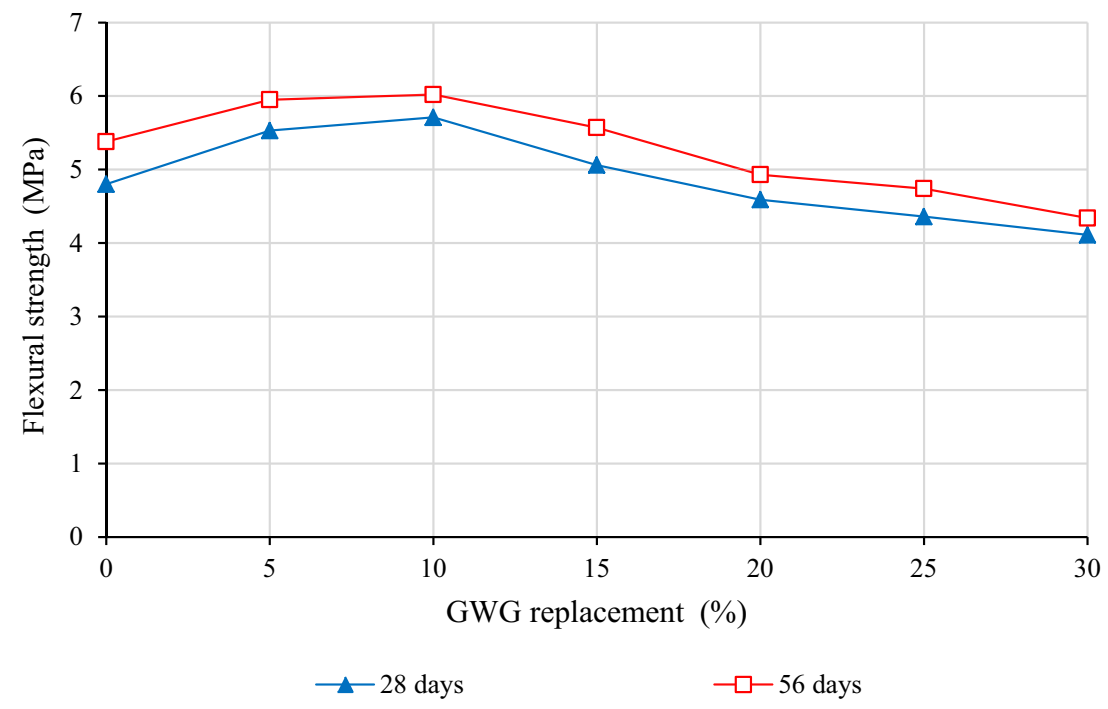

Fig. 12 Flexural strength versus GWG microparticles replacement as cementing material. 


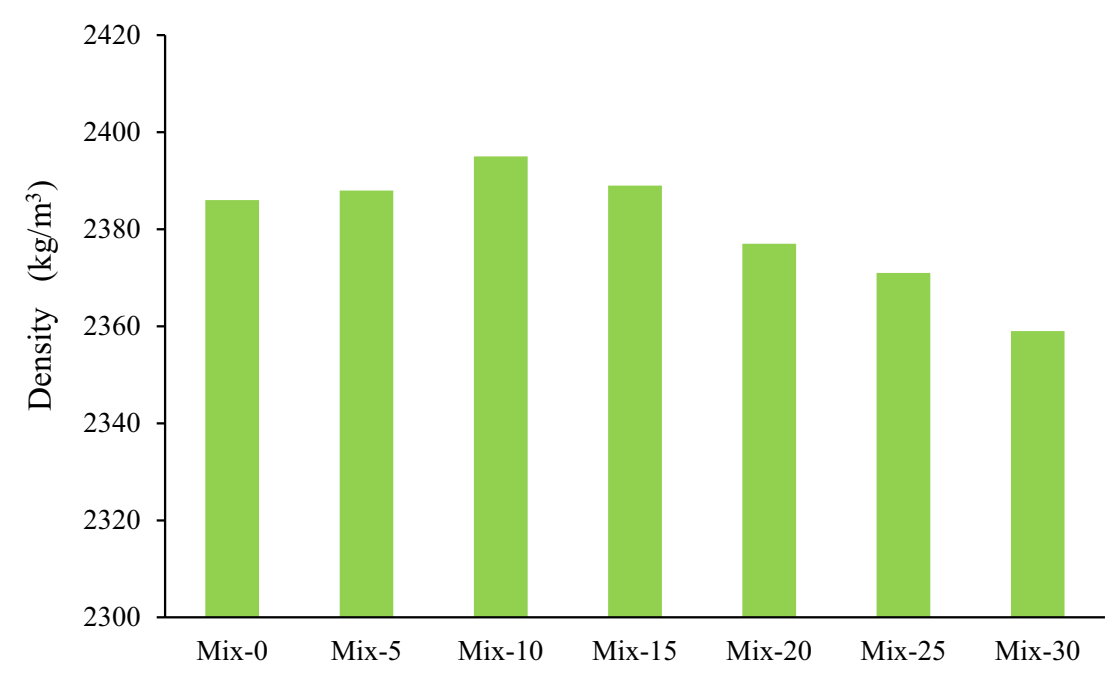

Fig. 13 Unit weights of SCCs incorporating partial level of GWG microparticles.

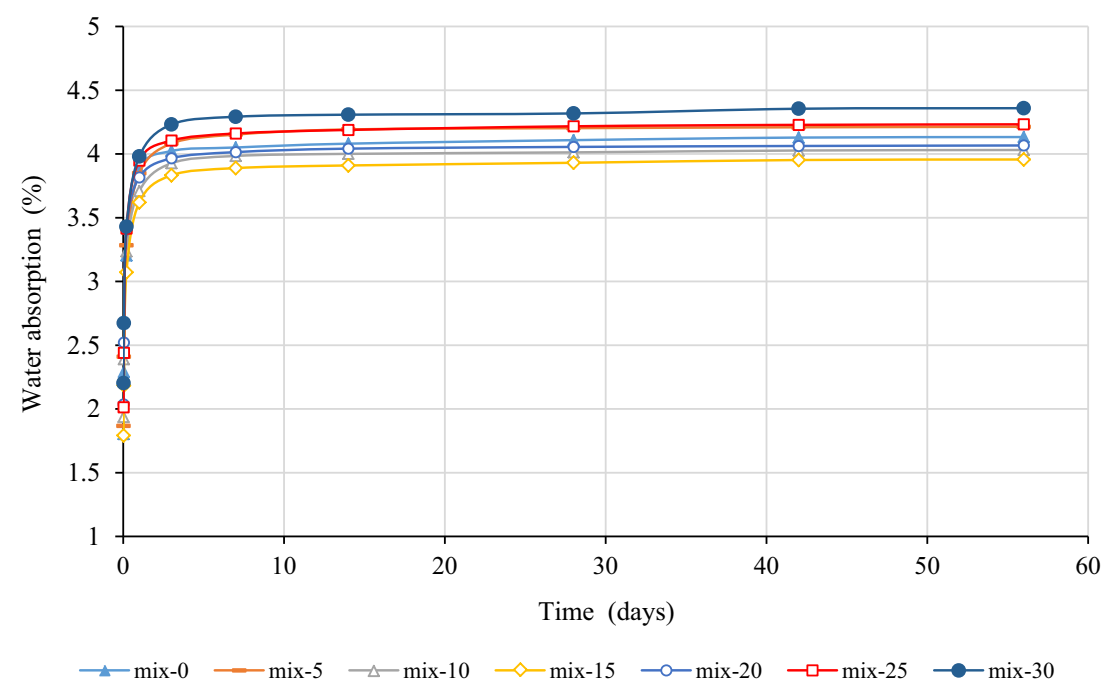

Fig. 14 Water absorption of SCCs incorporating partial level of GWG microparticles as ages.

to sufficient compaction (especially for SCC), hence more compressive strength and density. Besides, the pozzolanic grains fill the interface between aggregate and paste similar filler. Therefore, using GWG microparticles properly (up to $15 \%$ ), the density of concrete increases and vice versa porosity decreases. While the quantity of pozzolanic materials increases from the required amount for hydration process the silica leaching out; hydration product decreased and pores increase and consequently densities decrease. The other reason which made the unit weights of concretes containing GWG substitute decrease, is the less specific density of glass compare to cement. Therefore, with an increase in glass content, the weight of concrete mixes decrease because the specific gravity of glass is lower than that of cement. Generally, when the weak interface zone between aggregate and paste of the concrete is reduced, the strength of the concrete may be increased.

\subsubsection{Water Absorption}

One of the most important issue that relates to durability is water absorption. For service life prediction and long term behavior of concrete the aforementioned test should be investigated deeply. Liu (2011) believes that water absorption phenomena can be one of the most important factor for predicting the concrete deterioration subjected to freezing and thawing cycling and carbonation. Figure 14 shows the water absorption results of SCCs. Note that the replacement of Portland cement with GWG microparticles more than $20 \%$, slightly increased water absorption. But the results showed that up to $20 \%$ GWG replacement the water absorption is less or could be compared with the control mix. This can be attributed to hydration process which is continuing at the later days in reason of the pozzolanic effects of remaining GWG powder. As one knows absorption is the amount and rate of water absorbed into the concrete pores by capillary suction. Therefore, as the capillary pores decreased by more hydration process, the absorption would be also decreased as ages consequently. In this reason when GWG content increases (i.e., Mix-30\%) the hydration products decreases and the water absorption increased slightly.

Figure 14 shows that the use of GWG significantly decreases the rate of water absorption of SCC with 
increasing curing ages. It is evident that in the early ages (up to 6 days) the water absorption is increased significantly, but it slow down afterward. This may be due to the pozzolanic activity of GWG during the curing time. All concrete mixtures under investigation showed the water absorption lower than $4.5 \%$. Moreover, the water absorptions were in the range of $1.8-2.2 \%$ at $30 \mathrm{~min}$, in the range of $4.1-4.31 \%$ at 28 days and in the range of $4.13-4.36 \%$ at 56 days. From the water absorption results, use of up to $20 \%$ volume ratio of GWG microparticles in SCC may not influence the durability more than cement. Totally from the water absorption results, use of GWG as cement substitute in SCC may not incur severe durability problems. Liu (2011) reported that at each age, the sorptivity values are similar, which shows that the current glass content does not significantly increase the water absorption. Figure 15 shows some specimens before absorption measurement.

\subsubsection{Free Drying Shrinkage}

Drying shrinkage defined as the time-dependent strain measured at constant temperature in an unloaded and unrestrained specimen (Tam et al. 2012). Free shrinkage tests can

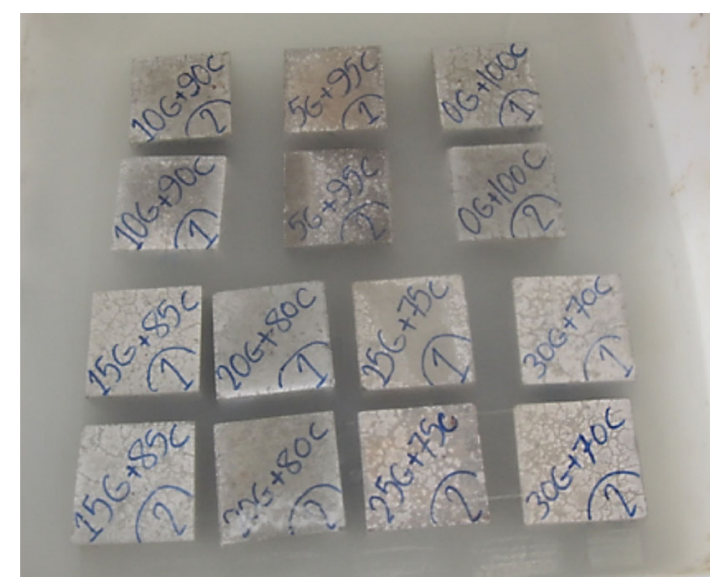

Fig. 15 Specimens before absorption measurement.

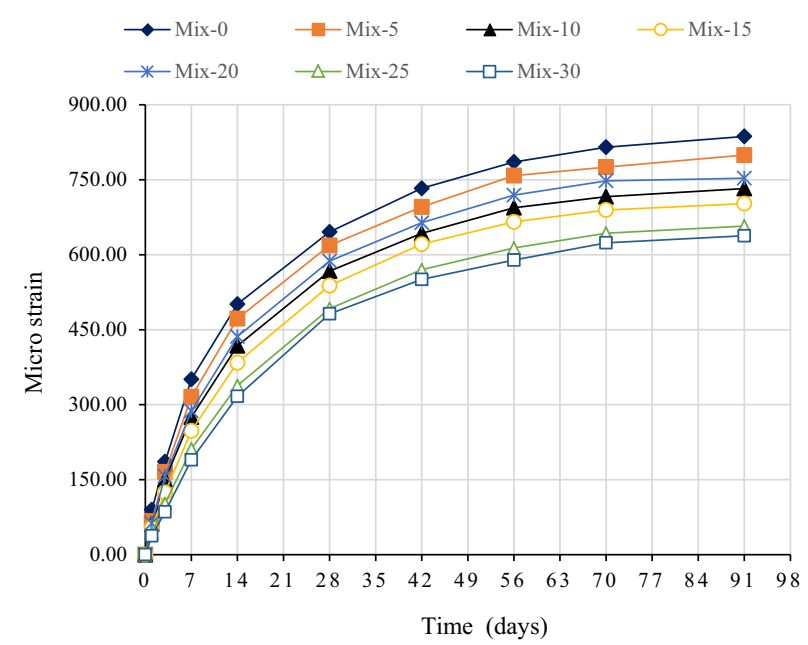

Fig. 16 Drying shrinkage of SCCs incorporating partial level of GWG microparticles as ages. provide necessary information on how the drying shrinkage stresses develop although they cannot offer sufficient information on the behavior of concrete structures (Wiegrink et al. 1996). As shown in Fig. 16, between 1 and 14 days, all mixes have the higher shrinkage rates. But, after this period time the shrinkage rates was decreased. A clear distinction was observed for different concretes with different GWG microparticles content, especially after about 14 days. Generally, the shrinkage strains were somewhat comparable at very early ages while there was a considerable distinction at later ages of the drying period. Tam et al. (2012) reported that this is mainly because of the loss of physically absorbed water from Calcium Silicate Hydrate $(\mathrm{C}-\mathrm{S}-\mathrm{H})$, resulting in a shrinkage strain. There are various factors influencing the drying shrinkage of hardened concrete. Water content is probably the largest single factor influencing the shrinkage of paste and concrete (Feldman and Hauang 1985a, b). Moreover, high paste content and the increasing use of admixtures may affect the shrinkage of concrete.

Based on the Australian Standard AS3600 provisions the acceptable value for shrinkage required a value below $0.075 \%$ at the age 56 days. From Fig. 16, it is evident that all of the concrete maintained below the acceptable value except the control mix. Therefore, this clarified that inclusion of GWG microparticles substitute in SCC improved the shrinkage performance. Mix-0 which contained no GWG showed shrinkage values larger than those of any of the other mixes. This may be attributed to existing more free water that do not combined in hydration process.

Mix-20 has $3.55 \%$ increase in the shrinkage strains compare to Mix-10 at 28 days. Mix-25 and Mix-30 have the lowest shrinkage strains among of all mixes, due to the combined effects of the decrease in the superplasticizer dosage and the increase in the GWG content that do not let to exist more free water in the paste. From the results (Fig. 16), the 91 days drying shrinkage of the concretes with $5,10,15,20,25$ and $30 \%$ GWG were $4.46,12.47,16.08$, $9.99,21.44$ and $23.75 \%$ lower than that of the control concrete (Mix-0), respectively. The shrinkage measuring apparatus used to determine the free drying shrinkage strain for SCCs is the concrete length comparator is shown in Fig. 17.

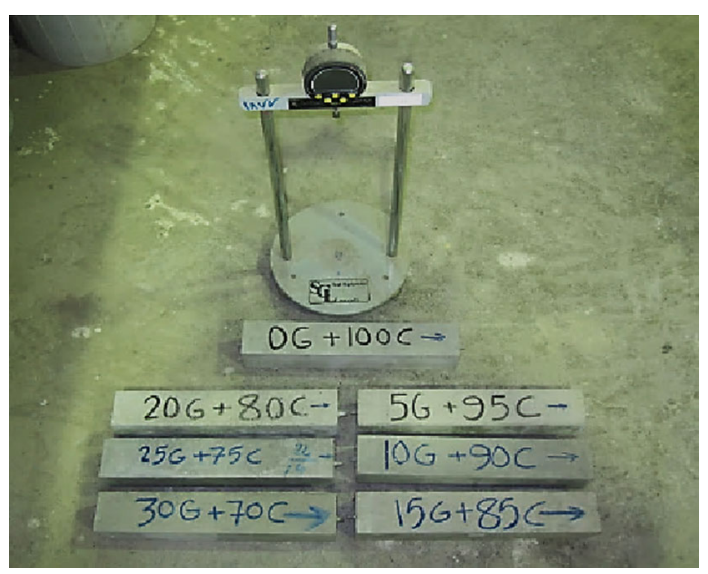

Fig. 17 Concrete length comparator. 


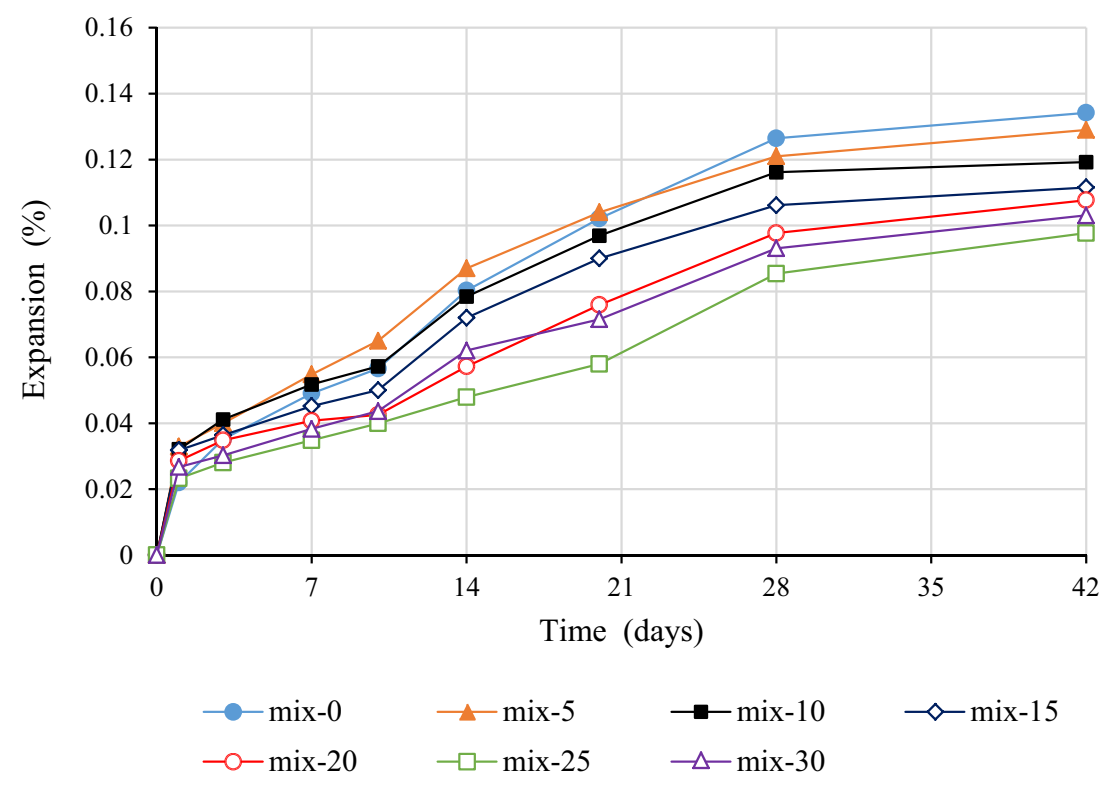

Fig. 18 ASR expansion of SCCs incorporating partial level of GWG microparticles as ages.
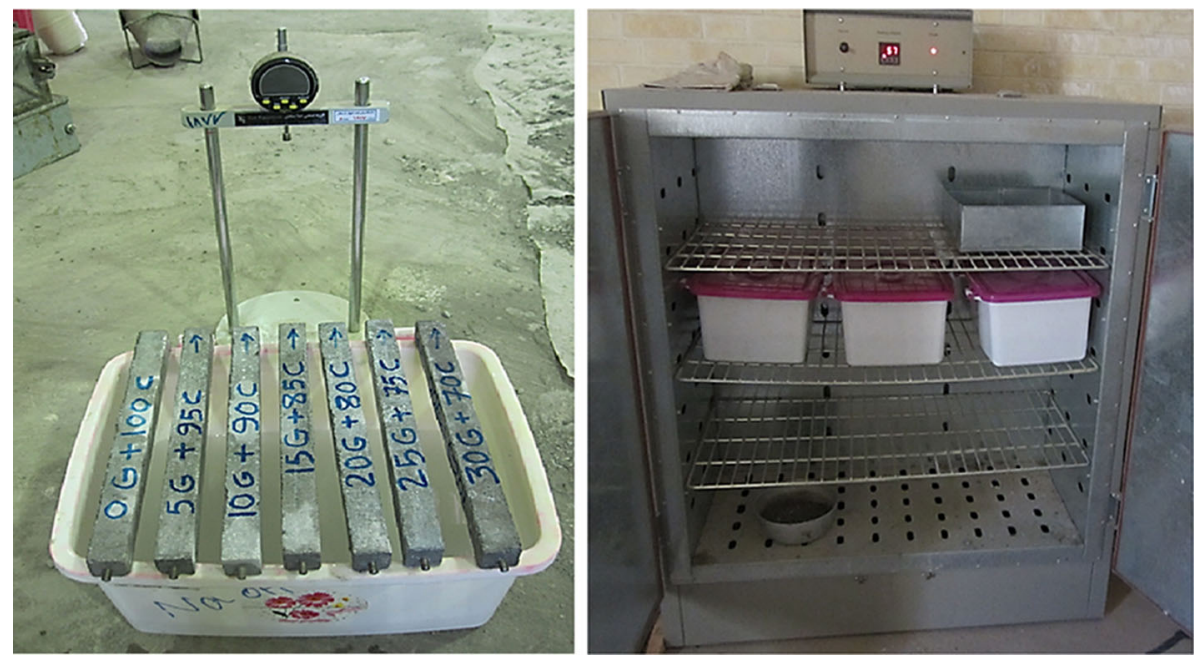

Fig. 19 Mortar bars stored in a $1 \mathrm{~N} \mathrm{NaOH}$ solution at $80^{\circ} \mathrm{C}$.

\subsubsection{ASR}

The ASR expansion of SCC mixtures at different ages are shown in Fig. 18. Each value presented is the average of two measurements. The ASR expansion was great up to 14 days. The suppressing effect of GWG microparticles on ASR expansion is very clear that the expansion at 14 days was less than $0.09 \%$ for all concrete mixtures, which is slightly lower than $0.1 \%$, as specified by ASTM C 1260 for innocuous reaction. As it is obvious glass contains high level of alkaline and it is able to be leached out and an expansion due to alkali aggregate occurred. A large number studies have confirmed that glass particles will not generate deleterious expansion themselves once they are smaller than $300 \mu$ (Meyer and Baxter 1997; Shi et al. 2004). The ASR expansion decreased with decreasing particle size of glass. This might be due to some glass containing high content of active silica can be classified as a reactive aggregate or a pozzolanic material (Shi et al. 2005; Zhu et al. 2009). Here, it is very clear that the expansion of mortar bar decreases as the GWG microparticles replacement level increases. One possible reason may be due to the highly reactive GWG microparticles which react with lime and form $\mathrm{C}-\mathrm{S}-\mathrm{H}$ gel which retains the alkalis in the $\mathrm{C}-\mathrm{S}-\mathrm{H}$.

From Fig. 18, when the amount of GWG microparticles increased from 0 to $5,10,15,20,25$ and $30 \%$, there was a gradual decrease in ASR expansion. Expansions at all ages however did not exceed $0.20 \%$, the allowable limits by ASTM 1260 (2007). Liu (2011) investigated the expansions in the ASR mortar bar tests of the mixes with and without glass. He reported that ASR expansion are similar to those of the control mix and all can be considered innocuous. This indicates glass incurs no more ASR risks than the cement in concrete. 
In brief no deleterious ASR expansion was occurred in the concrete specimens test, indicating that ASR would not be a problem in the presence of GWG microparticles. As previously stated this may have arisen because the pozzolanic reaction of GWG microparticles with cement appeared to enhance the binding of alkali, making it unavailable for reaction in other ways. After 42 days of curing, the surface of all mortar bars remained quite smooth and no cracks were observed. Mortar bars stored in a $1 \mathrm{~N} \mathrm{NaOH}$ solution at $80{ }^{\circ} \mathrm{C}$ are presented in Fig. 19.

\section{Concluding Remarks}

This paper presents the experimental results of a study on the feasible use of GWG microparticles as cementing material for the production of SCC. Based on the results of this study, the following conclusions can be presented:

1. The compressive, splitting tensile and flexural strengths of the GWG-SCCs increased with an increase in GWG microparticles content up to $20 \%$, vice versa as the GWG content increased more than $20 \%$ the strengths have been decreased. The concrete containing $5 \%$ GWG microparticles resulted in the highest strength properties. There was more than $18 \%$ improvement in the compressive strength of GWG-SCCs with $5 \%$ GWG microparticles substitution in comparison with the control mixture, but mixture containing $20 \%$ GWG was comparable to the control mixture. The variation of compressive strength is ranged $0,18.01,11.49,7.72,5.08,-3.99$ and $-10.15 \%$ from Mix-0 (control specimen) to Mix-30 containing $30 \%$ GWG, respectively.

2. The relationship between compressive strength and tensile splitting tensile strength located between the upper and lower bound per CIB-FIP code provisions.

3. The unit weight of the GWG-SCCs increased up to $15 \%$ GWG microparticles replacement, and for the mixes containing more than $15 \%$, it has been decreased. The unit weight and strengths behavior trends are similar.

4. Totally it was seen a decrease in the surface water absorption as GWG microparticles quantity increased up to $20 \%$. The variation of water absorption of GWGSCCs in 28 age is ranged $0,2,-3,-4 \%,-1,2$ and $4 \%$ from Mix-0 (control specimen) to Mix-30 containing $30 \% \mathrm{GWG}$, respectively.

5. The drying shrinkage of the GWG-SCCs decreased with an increase in the GWG microparticles content. The variation of drying shrinkage of GWG-SCCs in age 28 is decreasing in range $0,4,7,8,10,27$ and $45 \%$ from Mix-0 (control specimen) to Mix-30 containing $30 \%$ GWG, respectively.

6. The expansions in the ASR mortar bar tests of the mixes with GWG microparticles are similar to those of the control mix and all can be considered innocuous. This indicates GWG microparticles incur no more ASR risks than the cement in concrete.
7. From this study it may be concluded that the use of GWG microparticles as cement substitution improves ASR, drying shrinkage and workability characteristics, while the hardened behavior increases up to $20 \%$ replacement. The GWG microparticles in the range of 0-20\% may replace cement in concrete mixture. The economical SCC could be achieved with sufficient strength as the conventional concrete. Based on the materials used in this study, the results suggested that it is technically feasible to utilize GWG microparticles as a part of paste content in the production of SCC based on the present test results.

8. The improvement in the engineering and bulk properties of concrete mixtures incorporating GWG microparticles as cement indicates that GWG microparticles can be used beneficially as cementing material of SCC, however, additional experimental results are needed for micro properties of this type of concrete.

\section{Acknowledgments}

The authors are pleased to acknowledge the Roads and Urban Development Company of Kerman Province support. The experimental work of the present study was undertaken at the Institute for Concrete Research (ICR) of Rafsanjan University, Iran.

\section{Open Access}

This article is distributed under the terms of the Creative Commons Attribution 4.0 International License (http://creativecommons.org/licenses/by/4.0/), which permits unrestricted use, distribution, and reproduction in any medium, provided you give appropriate credit to the original author(s) and the source, provide a link to the Creative Commons license, and indicate if changes were made.

\section{References}

Afshoon, I., \& Sharifi, Y. (2014). Ground copper slag as a supplementary cementing material and its influence on the fresh properties of self-consolidating concrete. The IES Journal Part A: Civil \& Structural Engineering, 7(4), 229-242.

Alp, I., Deveci, H., \& Sungun, H. (2008). Utilization of flotation wastes of copper slag as raw material in cement production. Journal of Hazardous Materials, 159, 390-395.

Alya, M., Hashmi, M. S. J., Olabi, A. G., Messeiry, M., Abadir, E. F., \& Hussain, A. I. (2012). Effect of colloidal nanosilica on the mechanical and physical behavior of wasteglass cement mortar. Materials and Design, 33, 127-135.

ASTM C496/C496M-04. (2004). Standard test method for splitting tensile strength of cylindrical concrete specimens. West Conshohocken, PA: ASTM International. 
ASTM C1260-07. (2007). Standard specification for potential alkali reactivity of aggregates (mortar-bar method). West Conshohocken, PA: ASTM International.

ASTM C33/C33M-08. (2008). Standard specification for concrete aggregates. West Conshohocken, PA: ASTM International.

ASTM C403/C403M-08. (2008). Standard specification for time of setting of concrete mixtures by penetration resistance. West Conshohocken, PA: ASTM International.

ASTM C157/C157M-08. (2008). Standard specification for length change of hardened hydraulic-cement mortar and concrete. West Conshohocken, PA: ASTM International.

ASTM C150/C150M-09. (2009). Standard specification for Portland cement. West Conshohocken, PA: ASTM International.

ASTM C94/C94M-09. (2009). Standard specification for ready-mixed concrete. West Conshohocken, PA: ASTM International.

ASTM C231/C231M-09. (2009). Standard specification for air content of freshly mixed concrete by the pressure method. West Conshohocken, PA: ASTM International.

ASTM C494/C494M-10. (2010). Standard specification for chemical admixtures for concrete. West Conshohocken, PA: ASTM International.

Beltran, M. G., Barbudo, A., Agrela, F., Galvn, A. P., \& Jimenez, J. R. (2014). Effect of cement addition on the properties of recycled concretes to reach control concretes strengths. Journal of Cleaner Production, 79, 124-133.

Bingol, A. F., \& Tohumcu, I. (2013). Effects of different curing regimes on the compressive strength properties of self compacting concrete incorporating fly ash and silica fume. Materials and Design, 51, 12-18.

BS 1881: Part 116. (1983). Testing concrete: method for determination of compressive strength of concrete cubes. British Standard Institution (BSI).

BS 1881: Part 122. (1983). Testing concrete: Method for determination of water absorption. British Standard Institution (BSI).

BS EN 12390:2009. (2009). Part 7. Testing hardened concrete: Density of hardened concrete.

Carpenter, A. J., \& Cramer, S. M. (1999). Mitigation of ASR in pavement patch concrete that incorporates highly reactive fine aggregate (pp. 60-67). Transportation Research Record 1668, Paper No. 99-1087.

CEB-FIB model code 1990. (1993). Committee Euro-International du Beton. Thomas Telford, London, UK.

Chen, C. H., Huang, R., Wu, J. K., \& Yang, C. C. (2006). Waste E-glass particles used in cementitious mixtures. Cement and Concrete Research, 36, 449-456.

Craeye, B., Itterbeeck, P. V., Desnerck, P., Boel, V., \& De Schutter, G. (2014). Modulus of elasticity and tensile strength of self-compacting concrete: Survey of experimental data and structural design codes. Cement \& Concrete Composites, 54, 53-61.

Domone, P. L. (1997). A review of the hardened mechanical properties of self-compacting concrete. Cement and Concrete Composites, 29, 1-12.
Druta, C., Wang, L., \& Stephen, Lane D. (2014). Tensile strength and paste-aggregate bonding characteristics of self-consolidating concrete. Construction and Building Materials, 55, 89-96.

Du, H., \& Tan, K. H. (2013). Use of waste glass as sand in mortar: Part II-Alkali-silica reaction and mitigation methods. Cement \& Concrete Composites, 35, 118-126.

Dyer, T. D., \& Dhir, R. K. (2001). Chemical reactions of glass cullet used as cement component. Journal of Materials in Civil Engineering, 13(6), 412-417.

EFNARC. (2005). The European guidelines for self-compacting concrete: specification, production and use. The SelfCompacting Concrete European Project Group.

EN 1351:1997. (1997). Determination of flexural strength of autoclaved aerated concrete.

Federico, L. M., \& Chidiac, S. E. (2009). Waste glass as a supplementary cementitious material in concrete-critical review of treatment methods. Cement \& Concrete Composites, 31, 606-610.

Feldman, R. F., \& Hauang, C. Y. (1985a). Properties of Portland cement-silica-fume pastes I: Porosity and surface properties. Cement and Concrete Research, 15(5), 765-774.

Feldman, R. F., \& Hauang, C. Y. (1985b). Properties of Portland cement-silica-fume pastes II: Mechanical properties. Cement and Concrete Research, 15(6), 943-952.

Guneyisi, E., Gesoglu, M., \& Ozbay, E. (2010). Strength and drying shrinkage properties of self-compacting concretes incorporating multi-system blended mineral admixtures. Construction and Building Materials, 24, 1878-1887.

Hameed, M. S., Sekar, A. S. S., \& Saraswathy, V. (2012). Strength and permeability characteristics study of selfcompacting concrete using crusher rock dust and marble sludge powder. The Arabian Journal for Science and Engineering, 37, 561-574.

Jackson, N., \& Dhir, K. R. (1996). Civil engineering materials (5th ed.). London, UK: Macmillan Press Ltd.

Jain, J. A., \& Neithalath, N. (2010). Chloride transport in fly ash and glass powder modified concretes-influence of test methods on microstructure. Cement \& Concrete Composites, 32, 148-156.

Liu, M. (2011). Incorporating ground glass in self-compacting concrete. Construction and Building Materials, 25, 919-925.

Lotfy, A., Hossain, K. M. A., \& Lachemi, M. (2015). Lightweight self-consolidating concrete with expanded shale aggregates: Modelling and optimization. International Journal of Concrete Structures and Materials, 9(2), 185-206.

Mahmoud, E., Ibrahim, A., El-Chabib, H., \& Patibandla, V. C. (2013). Self-consolidating concrete incorporating high volume of fly ash, slag, and recycled asphalt pavement. International Journal of Concrete Structures and Materials, 7(2), 155-163.

Meyer, C., \& Baxter, S. (1997). Use of recycled glass for concrete masonry blocks final report 97-15. Albany, NY: New York State Energy Research and Development Authority. 
Mirzahosseini, M., \& Riding, K. A. (2014). Effect of curing temperature and glass type on the pozzolanic reactivity of glass powder. Cement and Concrete Research, 58, 103-111.

Nikbin, I. M., Beygi, M. H. A., Kazemi, M. T., Amiri, J. V., Rabbanifar, S., Rahmani, E., \& Rahimi, S. (2014). A comprehensive investigation into the effect of water to cement ratio and powder content on mechanical properties of self-compacting concrete. Construction and Building Materials, 57, 69-80.

Nuruddin, M. F., Chang, K. Y., \& Azmee, N. M. (2014). Workability and compressive strength of ductile self-compacting concrete (DSCC) with various cement replacement materials. Construction and Building Materials, 55, 153-157.

Okamura, H., \& Ouchi, M. (2003). Self-compacting concrete. Journal of Advanced Concrete Technology, 1(1), 5-15.

Oliveira, L. A., Castro-Gomes, J. P., \& Santos, P. (2008). Mechanical and durability properties of concrete with ground waste glass sand. In 11th international conference on durability of building materials and components, Istanbul, Turkey.

Park, S. B., Lee, B. C., \& Kim, J. H. (2004). Studies on mechanical properties of concrete containing waste glass aggregate. Cement and Concrete Research, 34, 2181-2189.

Parra, C., Valcuende, M., \& Gomez, F. (2011). Splitting tensile strength and modulus of elasticity of self-compacting concrete. Construction and Building Materials, 22, 201-207.

Ponikiewski, T., \& Golaszewski, J. (2014). The influence of high-calcium fly ash on the properties of fresh and hardened self-compacting concrete and high performance self compacting concrete. Journal of Cleaner Production, 72, 212-221.

Sfikas, I. P., Badogiannis, E. G., \& Trezos, K. G. (2014). Rheology and mechanical characteristics of self-compacting concrete mixtures containing metakaolin. Construction and Building Materials, 64, 121-129.

Shao, Y., Lefort, T., Moras, S., \& Rodriguez, D. (1999). Studies on concrete containing ground waste glass. Concrete and Cement Research, 30(1), 91-100.

Sharifi, Y., Hoshiar, M., \& Aghebati, B. (2013). Recycled glass replacement as fine aggregate in self-compacting concrete. Frontiers of Structural and Civil Engineering, 7(4), 419-428.

Sharifi, Y., Afshoon, I., \& Firoozjaie, Z. (2015). Fresh properties of self-compacting concrete containing ground waste glass microparticles as cementing material. Journal of Advanced Concrete Technology, 13(2), 50-66.

Shayan, A., \& Xu, A. (2006). Performance of glass powder as a pozzolanic material in concrete: A field trial on concrete slabs. Cement and Concrete Research, 36, 457-468.

Shi, C., Wu, Y., Shao, Y., \& Riefler, C. (2004). Alkali-aggregate reaction of concrete containing ground glass powder. In Proceedings of the 12th international conference on AAR in concrete (pp. 789-795).

Shi, C., Wu, Y., Riefler, C., \& Wang, H. (2005). Characteristics and pozzolanic reactivity of glass powders. Cement and Concrete Research, 35(5), 987-993.

Siddique, R. (2013). Compressive strength, water absorption, sorptivity, abrasion resistance and permeability of selfcompacting concrete containing coal bottom ash. Construction and Building Materials, 47, 1444-1450.

Tam, C. M., Tam, V. W. Y., \& Ng, K. M. (2012). Assessing drying shrinkage and water permeability of reactive powder concrete produced in Hong Kong. Construction and Building Materials, 26, 79-89.

Uysal, M. (2012). Self-compacting concrete incorporating filler additives: Performance at high temperatures. Construction and Building Materials, 26, 701-706.

Valcuendea, M., Parra, C., Marco, E., Garrido, A., Martínez, E., \& Cánoves, J. (2012). Influence of limestone filler and viscosity-modifying admixture on the porous structure of self-compacting concrete. Construction and Building Materials, 28, 122-128.

Wang, H. Y. (2011). The effect of the proportion of thin film transistor-liquid crystal display (TFT-LCD) optical waste glass as a partial substitute for cement in cement mortar. Construction and Building Materials, 25, 791-797.

Wang, H. Y., \& Huang, W. L. (2010). A study on the properties of fresh self-consolidating glass concrete (SCGC). Construction and Building Materials, 24, 619-624.

Wiegrink, K., Marikunte, S. M., \& Shah, S. P. (1996). Shrinkage cracking of high-strength concrete. ACI Materials Journal, 93(5), 409-415.

Zhu, H. Y., Chen, W., Zhou, W., \& Byars, E. A. (2009). Expansion behaviour of glass aggregates in different testing for alkali-silica reactivity. Materials and Structures, 42(4), 485-494.

Zong, L., Fei, Z., \& Zhang, S. (2014). Permeability of recycled aggregate concrete containing fly ash and clay brick waste. Journal of Cleaner Production, 70, 175-182. 